\title{
Optimised Scheduling of Water Supply Schemes
}

\author{
$\underline{\text { Y.V.Ng }}{ }^{\text {a }}$, I.R.Monks ${ }^{\text {a }}$ \\ ${ }^{a}$ City West Water, Sunshine North, Victoria, Australia \\ Email: $\underline{Y N g @ c i t y w e s t w a t e r . c o m . a u ~}$
}

\begin{abstract}
:
City West Water (CWW) provides water services to the city and western suburbs of Melbourne, Australia. As water becomes more precious, CWW has embarked on alternate water projects. Among them is the West Werribee Dual Water Supply Scheme (WWDWSS). CWW Engineering Department's Operations Research group built the Mass-Balance Model, MABAL to aid planning and to optimise the operating schedule of water schemes. An early simulation model has been replaced by a linear program to work around supply constraints. At the heart of MABAL, there are 3 models:

- Weather Forecasting: Statistical forecasts 28 days ahead

- Demand Forecasting: Uses weather data, customer numbers, time of year and other factors.

- Linear Programming: Optimises production, subject to supply constraints, to meet forecast demand.
\end{abstract}

While WWDWSS is under construction, MABAL is being applied to the Ballan Road water supply in Werribee as a pilot. The pilot provides better control of tank levels and makes efficient use of the pump station in response to increasing energy cost. The pilot provides an opportunity to prove the robustness and accuracy of the models and establish communication infrastructure and protocols between the software and the external SCADA devices. The linear programming, helps to overcome the problem of variable demand and supply outages. As a result, scheduling can be optimised. This paper describes the water supply schemes, with focus on the optimization model, the factors that influence the supply and demand sides and the outcomes.

To support the planning of the water supply scheme, MABAL allows the Engineer to define all of the components, the customers and their demand under different weather conditions and to model the operation over different periods. From these simulations the Engineer can change the settings to ensure that the water supply scheme is designed to avoid the need to add potable water to meet demand if the scheme is undersized. Also, to ensure that the scheme is not over-sized tying up valuable capital. Two configurations exist. One, GMABAL, allows water supply schemes ranging in complexity to be modeled for short periods of time. A second configuration, MABAL-LITE allows complex water supply schemes to be modeled for a much longer number of years while still achieving reasonable runtimes. MABAL has been used to assess the impact of an Aquifer to supplement the above ground storages for the WWDWSS. In particular to answer questions such as: When should above ground storages be doubled in capacity? Can the water supply scheme meet demand with just 2 salt reduction trains and if not when would I need to have a $3^{\text {rd }}$ salt reduction train? MABAL has also been used to determine the impact of an extended Feedwater supply outage of 4 months requested by Melbourne Water.

The development of the linear program model for MABAL has enabled CWW to realize the crucial planning issue of automated planning around future known events and quantity and quality constraints to produce a least cost operational schedule. City West Water has a tool that can be used to model proposed water and alternate water schemes. By running different scenarios through the model, water supply schemes can be planned to meet the critical issues of being configured to be the right-size and delivered at the right-time to balance supply and demand.

Results of the analysis can be included in business cases seeking approval for proposed water supply schemes. Different techniques and levels of generalization can be used to limit or reduce run times to have models solve in business acceptable times.

Operating water supply schemes have quite specific constraints that might be known when planning the scheme or they may be added as a consequence of restrictions imposed by external bodies when gaining approval to proceed with the water supply scheme. CWW has taken the view that operating water supply schemes will have customized models that best deal with each water supply scheme's individual requirements and so that acceptable solving times are achieved.

Keywords: Optimisation, Forecasting, Water, Scheduling, LINGO 


\section{INTRODUCTION}

City West Water (CWW) has responsibility for providing water services to the Melbourne CBD, northern suburbs and western suburbs. These include Werribee, one of the most rapidly growing areas of Australia and the location of Melbourne Water's Western Treatment Plant which collects sewerage from most of western and northern suburbs of Melbourne. WTP presents the opportunity to reduce the demand for potable (drinking) water by substituting recycled water for some end uses. CWW is building the West Werribee Dual Water Supply Scheme (WWDWSS) to provide water services to the new estates around Werribee.

For the WWDWSS, Class A Recycled Water is being purchased from Melbourne Water and then salt reduced to a level suitable for long term use on residential gardens, toilet flushing, parklands, the Werribee Racecourse, other commercial and industrial customers, and for fire-fighting.

WWDWSS has been conceived and designed by CWW's Water Innovations Department. The Engineering Department has responsibility for building and operating the water supply scheme. While traditional engineering tools include hydraulic models enable normal and peak flows to be modeled, the Operations Research group of the Engineering Department is assisting by applying statistical and optimization tools to develop a mass balance application, MABAL. The optimisation model has been configured in multiple forms to meet different needs and integrated into the Operational Mode of the application.

To support the planning of the scheme, MABAL allows the Engineer to define all of the components, the customers and their demand under different weather conditions and model the operation over different periods. From these simulations the Engineer can change the settings to ensure that the water supply scheme is designed to avoid the need to add potable water to meet demand if the scheme is under-sized. Also, to ensure that the scheme is not over-sized tying up valuable capital.

To support the operation of the scheme, Process Engineers use SCADA systems for monitoring of water supply schemes. But SCADA only deals with the current and historical performance of the scheme and to issue alarms when limits are breached. MABAL operates as a second level decision support system. It supports the forward planning of the operation of the scheme, MABAL collects information from a variety of sources, and uses it to develop an optimized schedule for processing, storing and delivering recycled water.

\section{OPTIMISATION ENGINE}

Early versions of the mass balance model used discrete period simulation and were prototyped in MS Excel and later upgraded to C\#.NET. In the model, components are defined for each stage of the scheme, new housing estates and their grow-out rates and demand under different weather conditions are recorded along with maintenance activity and randomly generated unscheduled outages.

The simulation approach took each interval in turn without considering future events. For example, a feedwater outage in the next two days would need to be met through potable water, because the simulation failed to look forward and recognise the need to over-produce and store during the lead up intervals in preparation for the coming supply shortfall. As such, there was a lack of forward looking of the model to plan around known outages and other supply limiting events and demand fluctuations.

Following a review of industry and technical papers and literature, the team turned to linear programming to overcome the shortfalls of the fixed interval simulation. Using LINGO, the viability of linear programming to solve the look-ahead issue was established and work started on further detailing the constraints and ensuring that the run time of the model was suitable for both planning and operational situations.

In response to specific needs four versions of the Linear Program have been prepared:

- Ballan Rd Potable Supply Scheme

- West Werribee Recycled Water Scheme

- MABAL-LITE

- GMABAL.

The four versions apply the same principles. The major controllable cost is energy as specific time periods are charged at either a peak or an off-peak rate. For recycled water schemes, penalty pricing applies when potable water is used as substitute for insufficient recycled water. By also including a "dummy" supply source, called "Unfilled demand", with an even more severe penalty price, supply always balances demand. 


\section{BALLAN ROAD POTABLE SUPPLY SCHEME MODEL}

The West Werribee Recycled Water scheme is under construction and will be commissioned during the 2013-14 business year. In the interim, a pilot project has been developed and installed around the Ballan Road Potable Supply scheme, BRdP.

BRdP is a water supply scheme for four housing estates around Werribee. Water is drawn from large Melbourne Water tanks at Cowies Hill and pumped to an elevated tank at Manor Lakes. When pumping, all customer demand is also met through the pump. When pumping stops customers of Manor Lakes Estate are supplied from the Manor Lakes tank under gravity feed. And, the customers of the other estates are gravity fed from Cowies Hill because a one-way valve stops water flowing back to them from the Manor Lakes elevated tank. This is illustrated in Figure 1.

The purpose of the pilot was to

- establish the infrastructure to automate the collection of data for the model and to communicate the model's operational schedule to the devices in the field.

- package the model application and work with the IT Department to deploy it into a production situation

- $\quad$ provide an opportunity for the Process Engineers to comment on the usability of the user interface.

- test the assumptions and recalibrate the model.

While the water supply scheme is relatively simple it provides

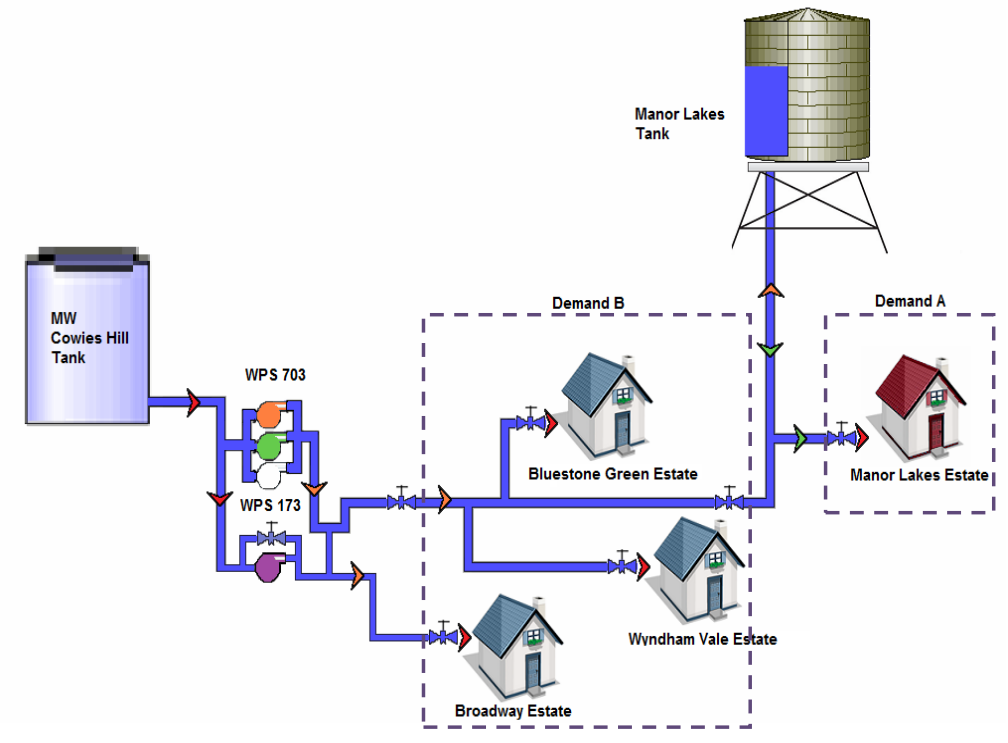

Figure 1: Ballan Road Potable Supply Scheme challenges to model accurately while serving the purposes of the pilot. In 2014, an upgrade to this scheme will form the potable part of the West Werribee Dual Water Supply Scheme. The schedule optimisation model for BRdP forecasts demand and supply for the next 7 days at 1 hour intervals (168 intervals).

Weather condition forecasting is based on a time series analysis. The demand forecast takes the predicted weather conditions and other factors into the bootstrap aggregation model (Treebagger function in Matlab).The linear programming model is formulated as follow:

\section{The model's objective function:}

Minimize :

$$
\begin{aligned}
& \sum_{s=1}^{2} \sum_{t=1}^{168}\left[P k_{t} \times P k t \times P e C_{s} \times p u D_{s, t}\right]+\left[\left(1-P k_{t}\right) \times O P k t \times P e C_{s} \times p u D_{s, t}\right]-- \text { CostOfPumpToDemand } \\
& +\sum_{s=1}^{2} \sum_{t=1}^{168}\left[P k_{t} \times P k t \times P e C_{s} \times p u T_{s, t}\right]+\left[\left(1-P k_{t}\right) \times O P k t \times P e C_{s} \times p u T_{s, t}\right]-- \text { CostOfPumpToTank } \\
& +\sum_{t=1}^{168} \text { InvC } \times \text { gravfT } t+\sum_{t=1}^{168} U n f D C \times \text { unfD } t+\sum_{t=1}^{168} P s C \times P_{t} \\
& --- \text { CostOfGravFlowFromTank }+ \text { CostOfUnfilledDemand }+ \text { CostOfPumping }
\end{aligned}
$$

The model's main constraints:

$$
\begin{array}{ll}
\operatorname{gravfT}_{t}=\operatorname{DemaA}_{t} \times\left(1-P_{t}\right) \quad, \quad 1 \leq t \leq 168 & \operatorname{gravfCH}_{t}=\operatorname{DemaB}_{t} \times\left(1-P_{t}\right) \quad, \quad 1 \leq t \leq 168 \\
\left(\sum_{s=1}^{2} p u T_{s, t}\right)+\operatorname{IniTInv}=t \operatorname{In} v_{r}+\operatorname{gravfT} T_{t}, t=1 & \left(\sum_{s=1}^{2} p u T_{s, t}\right)+t \operatorname{In} v_{t-1}=t \operatorname{Inv} v_{t}, \quad t \geq 2, t \leq 168
\end{array}
$$




$$
\begin{aligned}
& p u D_{s, t}+\text { puT }_{s, t} \leq P_{t} \times \text { PuEffVol }_{s} \times \text { PupTAvai }_{s, t} \quad, \quad 1 \leq s \leq 2 \quad, \quad 1 \leq t \leq 168 \\
& \left(\sum_{s=1}^{2} p u D_{s, t}\right)+u n f D_{t}=\left(\text { DemaA }_{t}+\text { DemaB }_{t}\right) \times P_{t} \quad, \quad 1 \leq t \leq 168
\end{aligned}
$$

Where $t$ is the time interval, $s$ is the pump steps,

$$
\begin{aligned}
& P k_{t}=1 \text { when period } t \text { is peak and } \\
& 0 \text { when period } t \text { is offpeak } \\
& P_{t}=1 \text { if wps703 is pumping and } \\
& 0 \text { if wps703 is not pumping } \\
& \mathrm{PeC}_{s}=\text { cost of pump in pump steps } s \\
& \text { DemaA }_{t}=\text { total customers area A demand period } t \\
& \text { IniTInv = Initial Manor Lakes Inventory } \\
& \text { UnfDC = unfilled demand cost } \\
& p u D_{s, t}=\text { pump steps } s \text { from wps703 pump } \\
& \text { stations to Demand period } t \\
& \text { gravf }_{t}=\text { gravity flow from Manor Lakes tank } \\
& \text { period } t \\
& \text { PupTAvai }_{s, t}=\text { wps703 pump to tank pumps available } \\
& P k t=\text { peak tariff } \\
& O p k t=\text { offpeak tarrif } \\
& \operatorname{InvC}=\text { inventory cost } \\
& P s C=\text { pump start cost } \\
& \text { PuEffVol }_{s}=\text { pump efficiency volume basis } \\
& \text { DemaB }_{t}=\text { total customers area } \mathrm{B} \text { demand period } t \\
& t I n v_{t}=\text { Manor Lakes Inventory period } t \\
& \text { unfD } D_{t,}=\text { unfilled demand period } t \\
& p u T_{s, t}=\text { pump steps } s \text { from wps703 pump } \\
& \text { stations to Manor Lakes tank period } t \\
& \text { gravf } \mathrm{CH}_{t}=\text { gravity flow from Cowies Hill tank }
\end{aligned}
$$

\section{Issues encountered when developing the model.}

1. During the initial development phase, the inventory for Cowies Hill tank was not introduced as a decision variable, this is because of its unlimited supply to customers of area B when the pump station is turned off. As such, the total demand supplies from Manor Lakes tank to customers area B $\left(\right.$ Dema $\left._{t}\right)$, see Figure 1. It was calculated by dividing the pump to demand with the ratio of number of residential. But this leads to infeasible solution as it is believed that the demand B is dependent on input data of DemaA $_{t}$. A decision variable for Cowies Hill inventory and its gravity flow value was created and the initial inventory set at a very high value of $9000 \mathrm{ML}$ in order to meet its unlimited supply capability.

2. Solving time was unacceptably slow (> 60 minutes). The use of Megalitres was causing poor scaling so rescaling the Megalitres (ML) to Kilolitres(KL) and to Litres (L) was tested. The attempt was successful and vastly improved the solving time to less than a minute. After a comparison of the two models, the use of KL gave the best results, so it was decided that the model would be converted into KL.

\section{WEST WERRIBEE RECYCLED WATER SCHEME}

The version of the MABAL model required for the West Werribee Recycled Water Scheme has many more types of customers to consider, supply constraints imposed by Melbourne Water, Salt Reduction Plant (SRP) operational constraints imposed by the operator, water quality constraints imposed by the environmental Protection Authority and demand patterns more dependent on weather conditions and time of year. The scheme is illustrated in Figure 2.

The model predicts the weather and forecasts the demand. Daily supply of feedwater varies due to scheduled outages for maintenance. The current tank levels and water quality levels are obtained from SCADA instruments. The data is aggregated into the interval periods and fed into the model.

Each day, the model generates a least cost operational schedule at 8 hour intervals for the next 28 days ( 84 intervals). It is published to the operator of the SRP, once a week as a firm order for 7 days and as an

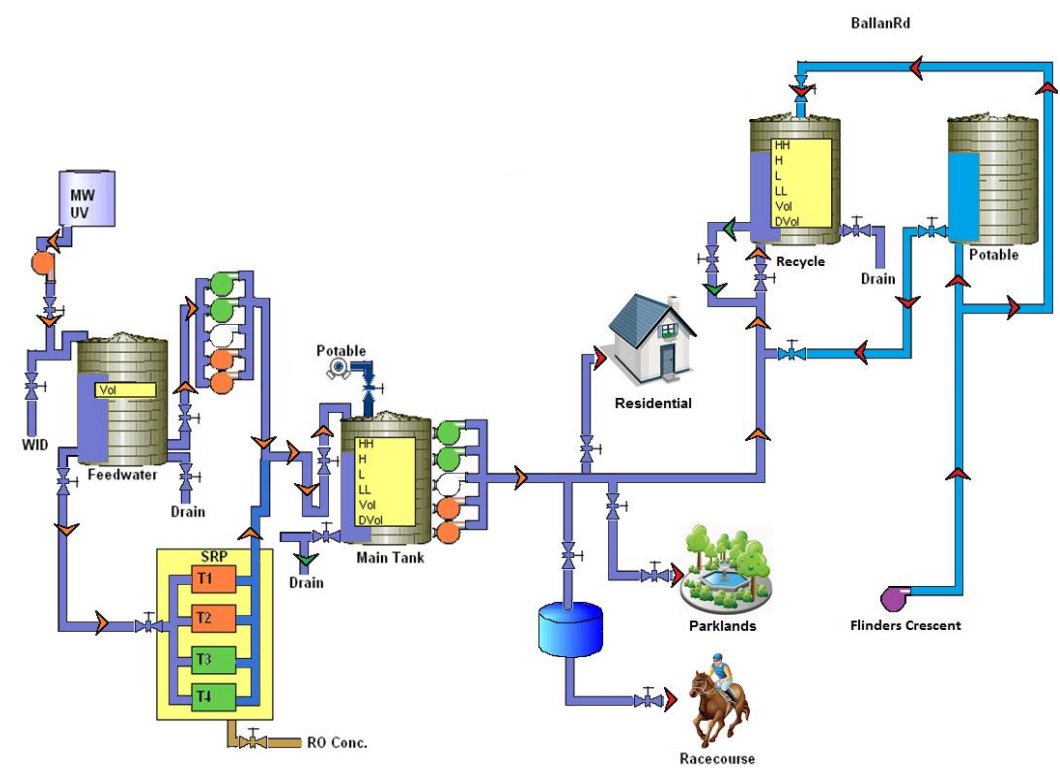

Figure 2: West Werribee Recycled Water Scheme 
indicative order for the 21 days after that to enable the operator to plan their operation around production. The daily re-calculation of the schedule allows the Process Engineers to monitor actual demand against the modeled operational schedule to determine if any corrective action is required.

\section{The model's objective function:}

Minimize:

$$
\begin{aligned}
& \sum_{r=1}^{2} \sum_{t=1}^{84}\left[\operatorname{SrpInC}_{r} \times \operatorname{srpin}_{r, t}\right]+\left[\operatorname{SrpStart}_{r} \times \text { srpstart }_{r, t}\right]--- \text { CostOfSRPProduction }_{84} \\
& +\sum_{t=1}^{84} F w M C \times\left(f w M_{t}+f w M E x c_{t}\right)---C o s t O f F l o w T o M a i n \\
& +\sum_{t=1}^{84}\left[\text { Pk }_{t} \times \text { PotFwCPk } \times \text { potM }_{t}\right]+\left[\left(1-P k_{t}\right) \times \text { PotFwCOPk } \times \text { potM }{ }_{t}\right]-- \text { CostOfPotableToMain } \\
& +\sum_{s=1}^{4} \sum_{t=1}^{84}\left[P k_{t} \times P k t \times P e C_{s} \times m p D_{s, t}\right]+\left[\left(1-P k_{t}\right) \times O P k t \times P e C_{s} \times m p D_{s, t}\right]---C o s t O f M a i n T o D e m a \\
& +\sum_{s=1}^{4} \sum_{t=1}^{84}\left[P k_{t} \times P k t \times P e C_{s} \times m p B r_{s, t}\right]+\left[\left(1-P k_{t}\right) \times O P k t \times P e C_{s} \times m p B r_{s, t}\right]--C_{\text {ostOfMainToBallan }} \\
& +\sum_{t=1}^{84}\left[P k t \times P o t B r P k \times p o t B r_{t}\right]+\left[\left(1-P k_{t}\right) \times P o t B r O P k \times p o t B r_{t}\right]-- \text { CostOfPotableToMain } \\
& +\sum_{t=1}^{168} \operatorname{Inv} C \times g r a v f B r_{t}+\sum_{t=1}^{84} B p D C \times b p D_{t}+\sum_{t=1}^{168} U n f D C \times u n f D_{t}+\sum_{d=1}^{30} d \times a D i r t y P_{d} \\
& \text {---CostOfGravFlowFromBallan+CostOfBallanPToDema+CostOfUnfilledDemand+CostOfLowWaterQuality }
\end{aligned}
$$

\section{The model's main constraints:}

$$
\begin{aligned}
& \left(\sum_{r=1}^{2} \text { srpout }_{r, t}\right)=\operatorname{srpM}_{t}, 1 \leq t \leq 84 \quad \text { for TedFixO } \text { Te }_{t}=1,\left(\sum_{r=1}^{2} \text { srpout }_{r, t}\right)=\text { TedO }_{t}, 2 \leq t \leq 84 \\
& f w S_{t}+f w \operatorname{In} v_{t-1}=f w \operatorname{In} v_{t}+f w S R P_{t}+f w M_{t}+f w M E x c_{t} \quad, \quad 1 \leq t \leq 84 \\
& m p D_{s, t}+m p B r_{s, t} \leq \text { PuEffNol }_{s} \times M p B r A v a i_{s, t} \quad, \quad 1 \leq s \leq 4,1 \leq t \leq 84 \\
& m g L P o t \times p o t M_{t}+\operatorname{SrpMTDS} \times \operatorname{srpM}_{t}+F w M T D S_{t} \times f w M_{t} \leq \\
& \operatorname{MgLMax} \times\left(\operatorname{pot}_{t}+\operatorname{srpM}_{t}+f w M_{t}\right) \quad, \quad 1 \leq t \leq 84 \\
& f w M_{t}+f w M E x c_{t}+\operatorname{srpM}_{t}+m \operatorname{In} v_{t-1}=m \operatorname{In} v_{t}+m p B r_{t}+m p D_{t} \quad, \quad 1 \leq t \leq 84 \\
& \operatorname{potBr}_{t}+m p B r_{t}+b r \operatorname{In} v_{t-1}=b r \operatorname{In} v_{t}+g r a v f B r_{t} \quad, \quad 1 \leq t \leq 84 \\
& m p D_{t}+\operatorname{gravfBr} r_{t}+u n f D_{t}+b p D_{t}=D_{t} \quad, \quad 1 \leq t \leq 84
\end{aligned}
$$

Where $r$ is the srp train, $s$ is the pump steps, $t$ is the time interval (when $t=1, t-1$ is initial inventory),

$$
\begin{aligned}
\operatorname{SrpInC}_{r}= & \text { Srp production cost } \\
\operatorname{srpM}_{t}= & \text { flow from SRP train to Main period } t \\
\operatorname{srpin}_{r, t}= & \text { flow from feedwater to SRP train } r \\
& \text { period } t \\
F w M C & \text { feedwater supply to main cost } \\
f w M_{t}= & \text { flows from feedwater to main period } t \\
f w M E x c_{t}= & \text { low quality water flows from } \\
& \text { feedwater to main period } t \\
f w I n v_{t}= & \text { feedwater inventory period } t \\
m p D_{s, t}= & \text { Main tank pumps demand on pump } \\
& \text { steps s to customers period } t
\end{aligned}
$$

$$
\begin{aligned}
\text { SrpStart }_{r}= & \text { Srp start cost } \\
\text { SrpMTTDS } & \text { TDS flows from Srp train to Main } \\
\text { srpout }_{r, t}= & \text { flow from SRP train } r \text { period } t \text { to } \\
& \text { Main } \\
F w M T D S= & \text { TDS flows from feedwater to main } \\
f w S_{t}= & \text { total supplies to feedwater period } t \\
f w S R P_{t}= & \text { flows from feedwater to SRP train } \\
& \text { period } t \\
m I n v_{t}= & \text { Main Inventory period } t \\
m p B r_{s, t}= & \text { Main tank pumps demand on pump } \\
& \text { steps s to Ballan Rd Recycle period } t
\end{aligned}
$$




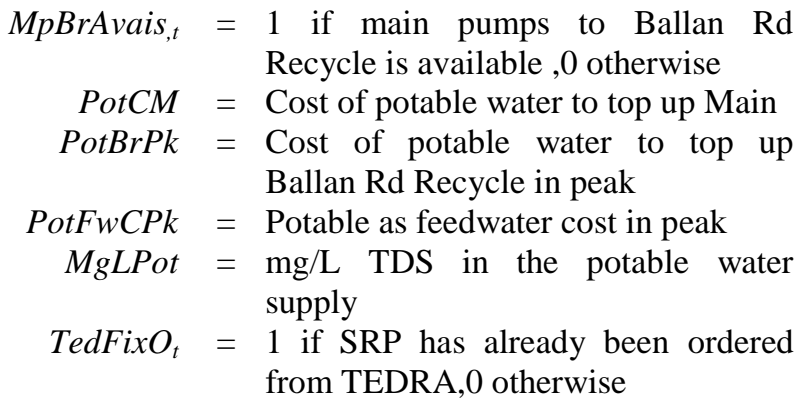

\author{
$b p D_{t}=$ Ballan Rd potable flows to Demand \\ period $t$ \\ $B p D C=$ Cost of Ballan Rd Potable to Demand \\ PotBrOPk = Cost of potable water to top up \\ Ballan Rd Recycle in offpeak \\ PotFwCOPk = Potable as feedwater cost in offpeak \\ MgLMax ${ }_{t}=$ preferred TDS supplied to demand \\ $T e d O_{t}=$ quantity ordered from TEDRA \\ $\operatorname{aDirty} P_{d}=$ another period of low water quality
}

\section{Issues encountered when developing the model.}

1. The complexity of the business rules lead to the decision to preprocess and post-process the data to minimise the work for the Linear Program.

2. The start-up and shut-down costs of pumps and the salt reduction trains startup cost were imposed to influence the model to maximise the run-time of these components.

3. The salt level of the Feedwater (TDS) and the membrane performance of the salt reduction trains means that the Total Dissolved Solids (TDS) needed to be a control variable. Maintenance outages can require the plant to run at higher salt levels for short periods. TDS values were switched to time based variables.

4. The initial model was built prior to the appointment of the SRP operator. Once appointed, fixed daily production steps and the 7-day fixed order was agreed and the constraint added.

5. Demand of some customers is unpredictable and impacts the 7-day fixed order strategy. A contingency demand is included at a higher level than used for BRdP to compensate.

\section{MABAL-LITE}

Specifically designed for Planning-mode. The MABAL-LITE version is a long-term strategic decision optimisation model capable of modeling water supply schemes over long periods with small intervals. For example, MABAL-LITE is capable of running a 40 year model at 8 hour intervals for the West Werribee Recycled Water scheme with an added Aquifer in 15 minutes.

MABAL-LITE is currently linked to flat data files for input and output. CWW intends to integrate MABALLITE into the MABAL Planning mode application. Figure 3 illustrated the graph of the WWDWSS with an added Aquifer.

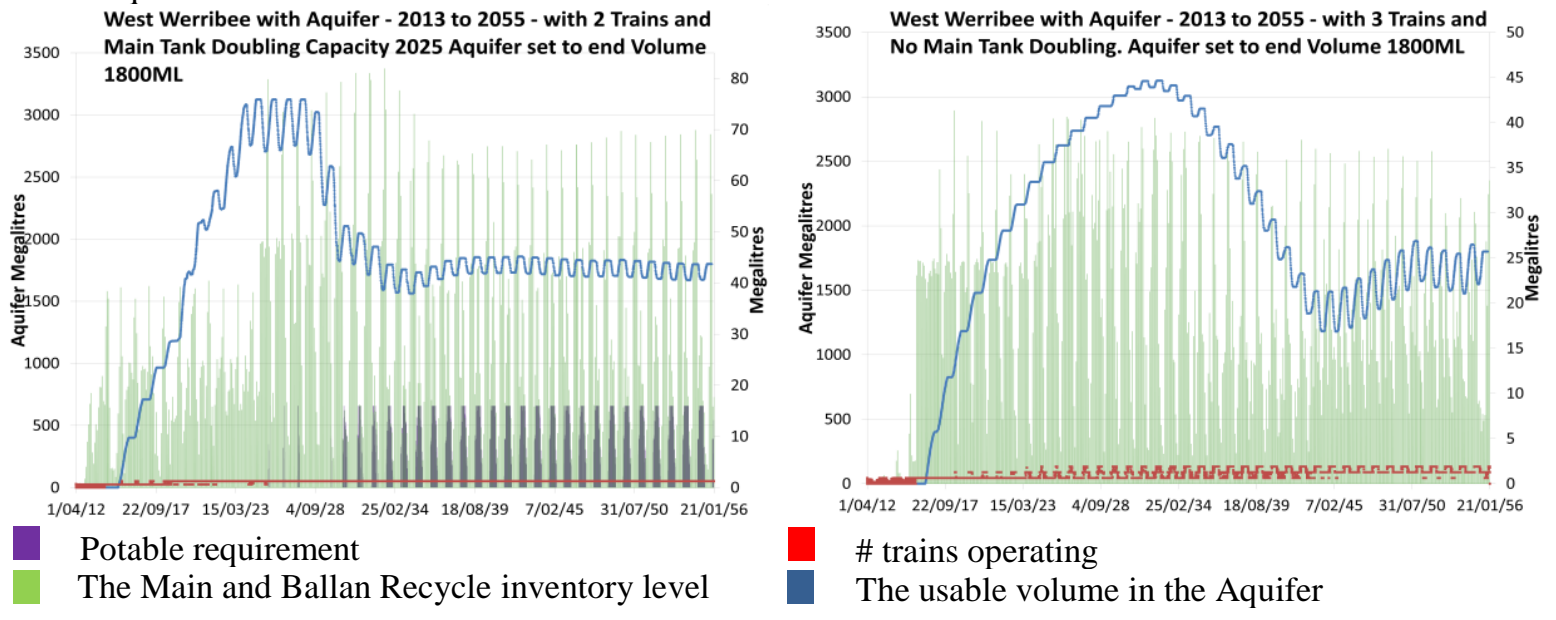

Figure 3: MABAL-LITE test results for tests 3 and 5. Test 3, which runs two trains, shows potable top up (purple )is required from the middle of the 40 year period, while no potable water is shown in test 5 which uses three trains and doubles the above ground storage earlier.

\section{GMABAL}

Specifically designed for Planning-mode, GMABAL (generalized MABAL) is capable of simulating a wide range of schemes at a high level of abstraction - see Figure 4. It is intended that GMABAL be used by the Planners at the conceptual design stage for water supply schemes to evaluate design ideas. 
Multiple water sources are permitted. Multiple customer demand points are permitted. Multiple water processing and storage components are permitted. Water losses between nodes can be modeled. Water quality rules can be included. Water supply scheme-specific constraints evident in the West Werribee Recycled or Ballan Rd Potable models are avoided in favour of generality ensuring a broader range of schemes that can be modeled.

GMABAL is currently linked to MS Excel data files for input and output. CWW intends to integrate GMABAL into the MABAL Planning mode application.

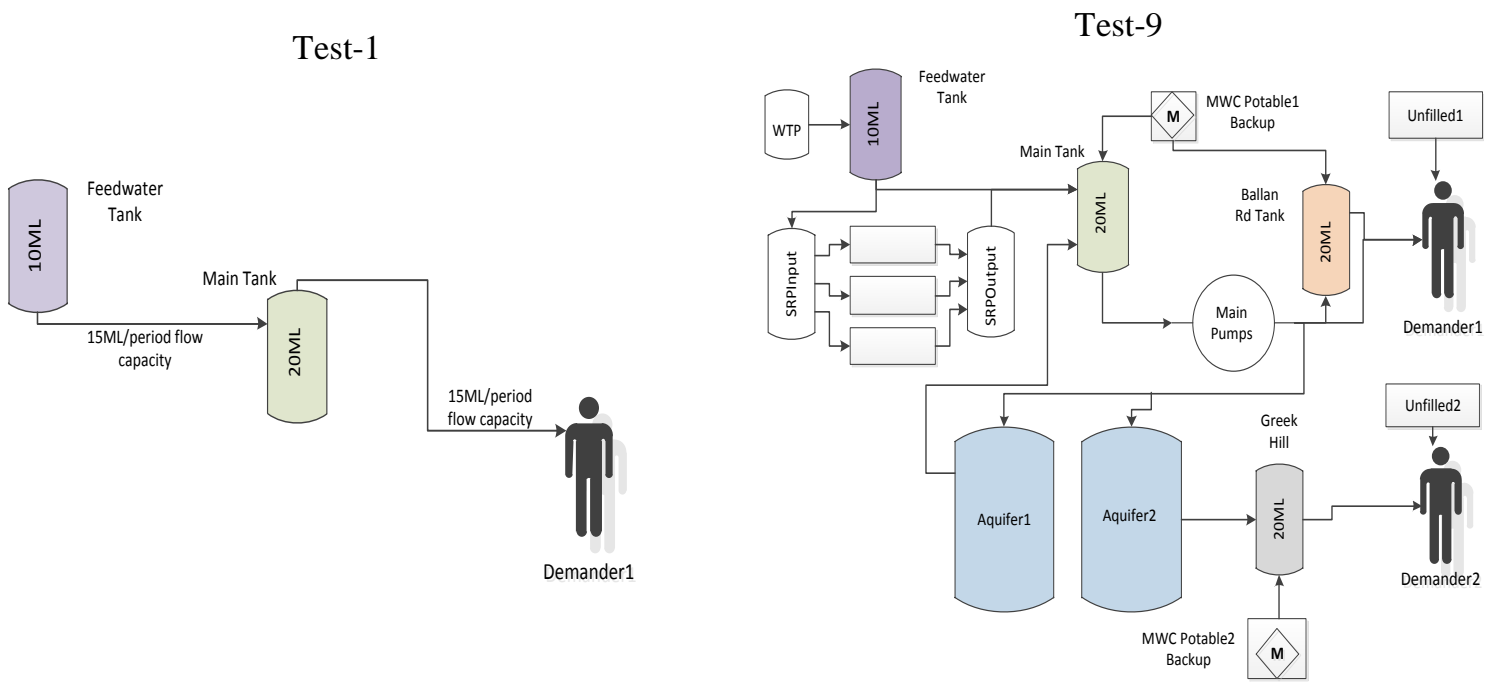

Figure 4: GMABAL modeled schemes: Test 1 (minimal configuration) and Test 9 (complex multiple components and customers scheme).

\section{OUTCOMES}

The development of the linear program model for MABAL has enabled CWW to realize the crucial planning issue of automated planning around future known events to produce a least cost operational schedule. CWW has a tool that can be used to model proposed water and alternate water schemes. By running different scenarios through the model, water supply schemes can be planned to meet the critical issues of being configured to be the right-size and delivered at the right-time to balance supply and demand.

Results of the analysis can be included in business cases seeking approval for proposed water supply schemes.

Different techniques and levels of generalization can be used to limit or reduce run times to have models solve in business acceptable times.

Operating water supply schemes have quite specific constraints that might be known when planning the water supply scheme or they may be added as a consequence of restrictions imposed by external bodies when gaining approval to proceed. $\mathrm{CWW}$ has taken the view that operating water supply schemes will have customized models that best deal with each water supply scheme's individual requirements and so that acceptable solving times are achieved.

In early, 2014 the WWDWSS will be commissioned and will start producing and delivering recycled water to the new estates and other customers. As an integral component of the commissioning, MABAL will be switched from simulating the operation to actual forecasting and controlling tank levels.

\section{ACKNOWLEDGEMENTS}

The authors acknowledge the contributions and advice of Mr Mark Wiley, Lindo Systems, Chicago, Dr Fritz Raffensperger, formerly Dept. of Management, Univ. of Canterbury, Christchurch, Dr Thomas Knowles, Professor of Management Science at the Stuart School of Business of the Illinois Institute of Technology (Chicago).

The authors also acknowledge the contribution and support of staff of the Engineering Dept and Water Innovations Dept, City West Water. 